\title{
Spontaneous Spinal Epidural Hematoma: A Case Report and Literature
}

\section{Review}

Badiaa Bannar $^{1 *}$, F. Jaafari ${ }^{1}$, B. Zouita ${ }^{1}$, D. Basraoui ${ }^{1}$, H. Jalal ${ }^{1}$

Department of Radiology, Mother and Child Hospital, Mohamed VI Hospital, Marrakech Morocco

DOI: $10.36347 /$ sjmcr.2021.v09i04.018

| Received: 26.02.2021 | Accepted: 29.03.2021 | Published: 22.04.2021

*Corresponding author: Badiaa Bannar

Abstract

Case Report

Spontaneous spinal epidural haematoma is defined as a bloody effusion in the epidural space occurring outside of any traumatic context. It is a rare but serious condition whose etiopathogeny is not always clear. The typical symptomatology is suggestive. Any suspicion of epidural haematoma should motivate an urgent diagnostic and therapeutic approach because the functional and sometimes vital prognosis is at stake. This is a case of rapidly progressive tetraparesis in a 22 year old woman, pregnant at 32 weeks' gestation with no notion of spinal trauma and no particular history. The medical imaging by angiography and MRI had made it possible to eliminate a vascular malformation and to make the diagnosis. The patient underwent emergency surgery and the postoperative course was simple. Symptomatic cervical epidural haematomas must be diagnosed early in order to consider appropriate treatment. The patient's functional and even vital prognosis will depend on this treatment.

Keywords: Haematoma, Epidural, Cervical, MRI.

Copyright $(02021$ The Author(s): This is an open-access article distributed under the terms of the Creative Commons Attribution 4.0 International License (CC BY-NC 4.0) which permits unrestricted use, distribution, and reproduction in any medium for non-commercial use provided the original author and source are credited.

\section{INTRODUCTION}

The development of medical imaging means, in particular CT and MRI, which are becoming more and more efficient, has made it possible to diagnose spontaneous epidural haematomas easily and early, when they are compressive or accompanied by a neurological disorder, which constitutes a surgical emergency. The aim of this work was to report a case of non-traumatic cervical haematoma.

\section{Clinical Case}

A 22 year old woman, 32 weeks pregnant, presented with a sudden paraplegia with anaesthesia in the saddle. The clinical examination showed a tetraplegia with $\mathrm{C} 4$ sensory level without diabetes or hypertensive peak.
An obstetrical ultrasound was performed without any abnormality and a complementary spinal cord MRI showed an intra canal, extra spinal, posterior epidural, declive collection, measuring 2.6 x $0.6 \mathrm{~mm}$, extended over $6 \mathrm{~cm}$, from C3 to C7, T1 hyper signal, T2 heterogeneous hyper signal, not erased after fat saturation, unchanged after PDC injection with signal void in $\mathrm{T} 2 *$, and scalloping on the medulla, extends intraforaminal left on two levels C5-C6 and C6-C7.

This formation is responsible for compression of the spinal cord, which is pushed forward and has a $\mathrm{T} 2$ hyper signal opposite $\mathrm{C} 5$ and $\mathrm{C} 7$ in relation to spinal cord injury. Postoperatively the patient had recovered her neurological deficit progressively. 
Badiaa. Bannar et al., Sch J Med Case Rep, Apr, 2021; 9(4): 367-369
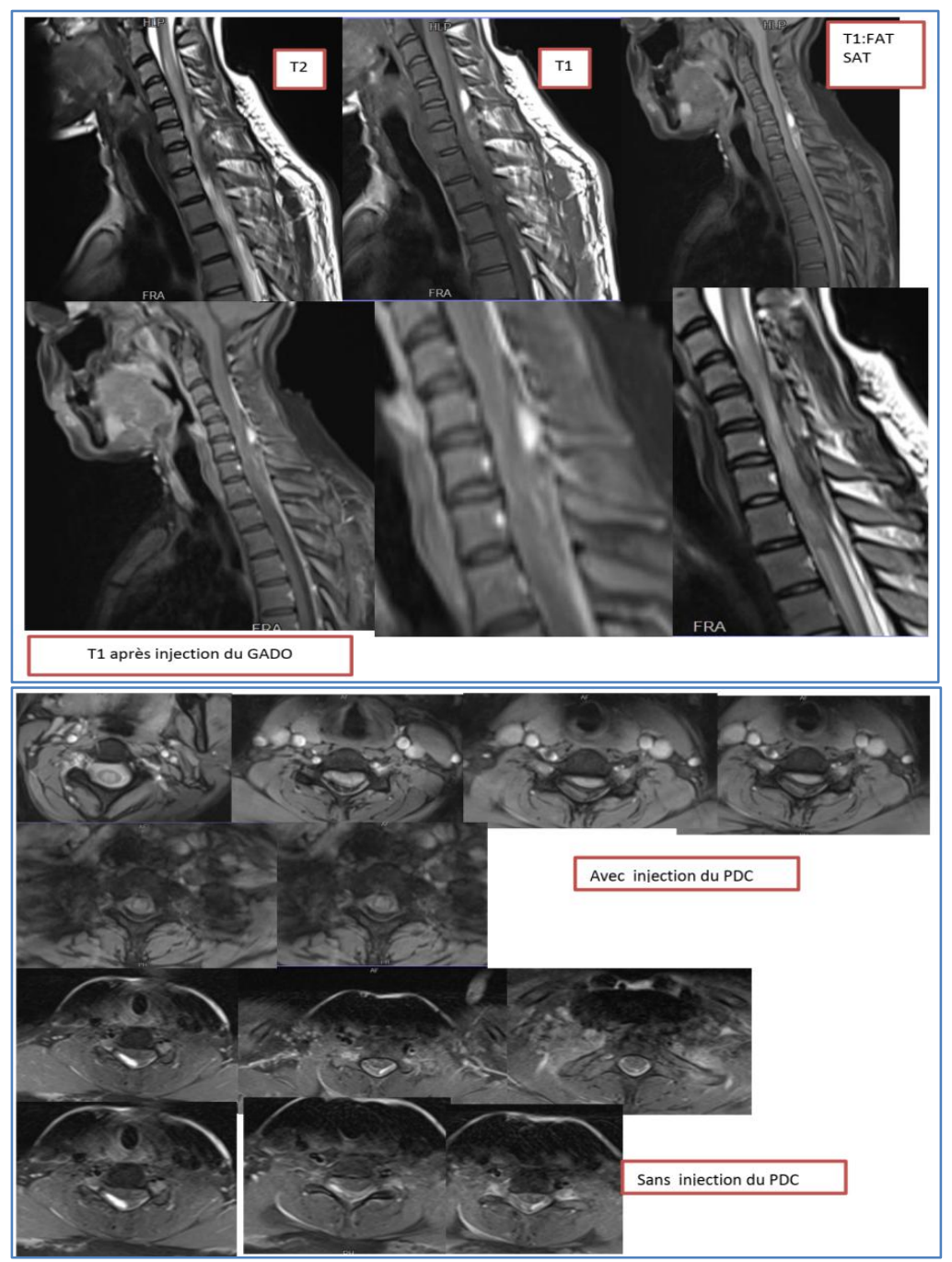

Fig-1: Individualization of an intraductal, extra spinal cord, posterior epidural, sloping, T1 hyper signal, T2 heterogeneous hyper signal, not erased after fat saturation, unchanged after PDC injection with T2* signal void, and scalloping on the medulla, extending into the left intraforaminal region on two levels $\mathrm{C5}-\mathrm{C6}$ and $\mathrm{C6}-\mathrm{C} 7$. This formation is responsible for compression of the spinal cord

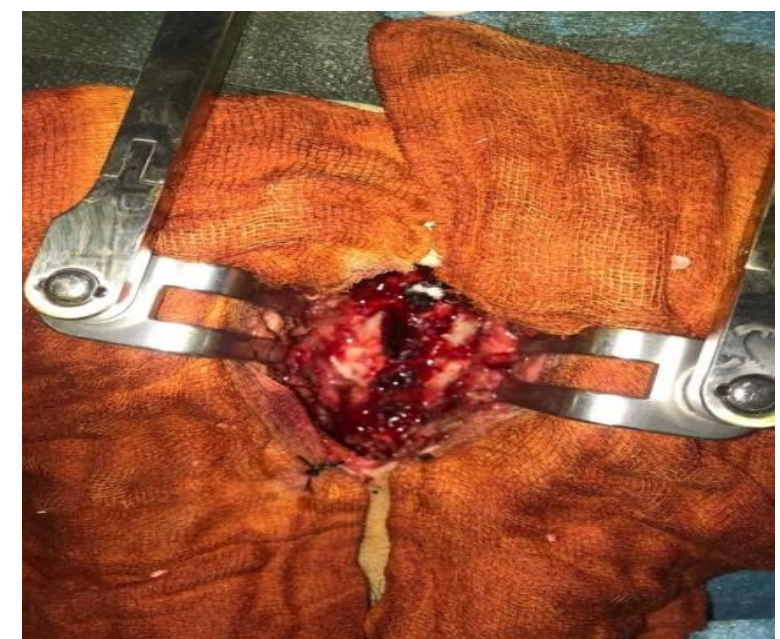

Fig-2: Intraoperative hematoma

\section{DISCUSSION}

Spontaneous cervical epidural haematomas, considered to be a rare condition [1, 5], are becoming increasingly frequent with the improvement of diagnostic methods, in this case the advent of magnetic resonance imaging. Predominantly a female condition, they are located preferentially in the cervical spine between $\mathrm{C} 5$ and $\mathrm{C} 7$ in $95 \%$ (all aetiologies considered), and from $\mathrm{C} 1$ to $\mathrm{C} 4$ in about $44 \%$ [3]. Groen found a higher frequency of locations on the posterior or posterolateral aspect of the dura mater where extensive epidural venous networks are located [3]. The grey areas surrounding the pathophysiology of this condition mean that the actual origin of the bleeding is still subject to controversy. Some authors favour a venous origin of the epidural bleeding, which would be favoured by an increase in intra thoracic pressure [7]. The low pressure of the epidural veins corroborates with the sudden onset of neurological signs in all four limbs. Hypotheses suggest a ruptured epidural AVM detectable by modern radiodiagnostic means [1], this malformation was not found in our patient. It is important to keep in mind that in $40-50 \%$ of cases, no cause for the epidural haematoma is found [2]. 
Magnetic resonance imaging is the examination of choice for the diagnosis and posttreatment follow-up of cervical epidural haematoma [1, 5]. Spontaneous cervical epidural haematoma with clinical expression is a neurosurgical emergency. The resulting spinal cord compression may be responsible for severe neurological impairment ranging from motor disability to death the closer one gets to $\mathrm{C} 1$ and the medulla oblongata. Cervical laminectomy and decompression of the medulla by evacuation of the haematoma is the most widely adopted surgical technique [1, 5]. This treatment must be performed within the first 12 hours after compression to expect a better result; this time frame can vary up to 24-48 hours after the onset of the first neurological signs [1, 5]. Conservative treatment, proposed by some authors [4], should only be considered if the patient is pauciously symptomatic and with little spinal cord compression on imaging. Corticosteroid therapy 1 and physiotherapy should be part of the therapeutic arsenal. They help to promote the patient's neurological recovery.

\section{CONCLUSION}

Spontaneous cervical epidural haematoma is becoming increasingly frequent and constitutes a surgical emergency. Early therapeutic management guarantees a better therapeutic result. The progress made in medical imaging allows an early diagnosis.

\section{REFERENCES}

1. Diallo M, Boni N, Tokpa A, Bazézé V. Hématome épidural spontané cervical : Revue de la littérature à travers un cas, Le Rachis, Mars-Avril. 2014;2:3031.

2. Foo D, Rossier AB. Preoperative neurological status in predicting surgical outcome of spinal epidural haematomas. Surg Neurol. 1981; 15(5):389-401.

3. Groen RJ, Ponssen H. Vascular anatomy of the spinal epidural space: considerations on the etiology of the spontaneous spinal epidural hematoma. Clinical Anatomy: The Official Journal of the American Association of Clinical Anatomists and the British Association of Clinical Anatomists. 1991;4(6):413-20.

4. Lovblad KO, Baumgartner RW, Zambaz BD. Remonda L, Ozdaba C, Schroth G. Nontraumatic spinal epidural hematomas MR Features. Acta Radiol. 1997; 38:8-13

5. González AM, Cuello JP, Cruz PR, Mohedano AI, Rubio RD, Delgado FR, Pastor AG, de Villoria Lebiedziejswki JG, García PF, Martínez JR, Echevarri DE. Hematoma espinal epidural espontáneo: estudio retrospectivo de una serie de 13 casos; Neurología (NRL). 2014; 620; 7-8.

6. Taniguchi LU, Pahl FH, Lúcio JE, Brock RS, Gomes MQ, Adoni T, Fiorini VC, Carvalho RC, Evaristo EF, Mutarelli EG, Schettino G. Complete motor recovery after acute paraparesis caused by spontaneous spinal epidural hematoma: case report. BMC emergency medicine. 2011 Dec;11(1):1-4.

7. Tremolizzo L, Patassini M, Malpieri M, Ferrarese C, Appollonio I. A case of spinal epidural haematoma during breath-hold diving. Diving Hyperb Med. 2012 Jun 1;42(2):98-100. 